\title{
Changes in masa and tortillas obtained from maize irradiated and nixtamalized with nejayote**
}

\author{
C. Valderrama-Bravo ${ }^{1,2 *}$, F.A. Domínguez-Pacheco ${ }^{3}$, C. Hernández-Aguilar ${ }^{3}$, G. Sánchez-Hernández ${ }^{4}$, \\ C. Pérez-Reyes ${ }^{4}$, M. Contreras-Padilla ${ }^{5}$, T. Rojas-González ${ }^{1}$, and A. Oaxaca-Luna ${ }^{2}$
}

\begin{abstract}
${ }^{1}$ Faculty of Higher Studies Cuautitlan, National Autonomous University of Mexico (UNAM), Department of Engineering and Technology LEM-I (Laboratory of Experimental Multidisciplinary-Food Engineering), Campus 1, Primero de Mayo, Infonavit Centro, Cuautitlán Izcalli, State of Mexico C.P. 54725

${ }^{2}$ Faculty of Higher Studies Cuautitlan, National Autonomous University of Mexico (UNAM), Department of Mathematics, Campus 4, Km. 2.5 Carretera Cuautitlán-Teoloyucan San Sebastián Xhala, Cuautitlán Izcalli, State of Mexico, Mexico, C.P. 54714.

${ }^{3}$ National Polytechnic Institute, SEPI-ESIME Zacatenco, Professional Unit “Adolfo López Mateos”, Col. Lindavista, Mexico, D. F. C. P. 07738

${ }^{4}$ Faculty of Higher Studies Cuautitlan, National Autonomous University of Mexico (UNAM), UNIGRAS, Dr. Jorge Jimenez Cantu, Cuautitlan Izcalli, State of Mexico, Mexico C, P. 54729

${ }^{5}$ Faculty of Engineering, Autonomous University of Querétaro, Cerro de las Campanas s/n, Las Campanas, C.P. 76010 Santiago of Queretaro, Qro., Mexico
\end{abstract}

Received January 11, 2018; accepted June 11, 2018

\begin{abstract}
Maize grains were treated with electromagnetic fields and nixtamalized with nejayote, in order to analyze the effect of such treatments on the microbiological and viscoelastic properties of masa, and on sensory tests of tortilla. A sample of maize grains was irradiated by electromagnetic fields for 7 and $12 \mathrm{~min}$. Then, following the nixtamalization with nejayote, masa and tortillas were obtained. The application of electromagnetic fields did not decrease the growth of moulds in maize grains. However, a synergistic effect of irradiation (12 $\mathrm{min})$ and nixtamalization with diluted nejayote (50 water/50 whole nejayote) improved the sanitary quality of masa. Elastic and viscous moduli showed significant differences in all treatments. The masa from maize grains irradiated for $12 \mathrm{~min}$ showed the highest values of elastic and viscous moduli, while the masa from grains irradiated for $7 \mathrm{~min}$ and nixtamalized with diluted nejayote ( 70 water/30 whole nejayote) presented the lowest values. These results seem to indicate that the application of electromagnetic fields modifies the viscoelastic modulus of masa. Sensory tests showed that tortillas obtained from irradiated (12 min) maize grains, nixtamalized with nejayote (70 water/30 whole nejayote), had the highest score of all the attributes, i.e. texture, chewiness and taste.

Keywords: electromagnetic fields, masa, tortillas, viscoelastic properties
\end{abstract}

*Corresponding author e-mail: carmenvalde@yahoo.com.mx

**This work was supported by Research Unit in Grains and Seeds (UNIGRAS), Laboratory Experimental Multidisciplinary-Food Engineering (LEM I) and project PAPIME PE108316 (20162018) of the Faculty of Studies Cuautitlan Superiors-UNAM and ESIME-Zacatenco of IPN.

\section{INTRODUCTION}

Maize (Zea mays L.) is the most frequently produced grain in Mexico. It is commonly consumed as tortillas which represent the main source of calories for low-income households (Bello-Pérez et al., 2002). An average Mexican consumes more than $80 \mathrm{~kg}$ of maize tortillas annually (Serna-Saldivar and Chuck-Hernández, 2016). During the nixtamalization process, in the steeping stage, there is a gradient of calcium concentration throughout the pericarp structure (Gutiérrez-Cortez et al., 2010, 2016), and maize grains absorb water and swell due to changes in moisture distribution (Martínez-Bustos et al., 2001). Also, Rodríguez et al. (1996), reported that nixtamalization at calcium hydroxide concentrations up to $0.2 \%$ increased tortilla crystallinity while higher concentrations decreased that parameter.

Fernández-Muñoz et al. (2011a, b) demonstrated that the presence of calcium increased the viscosity of nixtamalized flours by inhibiting starch gelling. Nevertheless, crystallinity and viscosity modifications of the starch granules could occur well before maize nixtamalization, which

(C) 2018 Institute of Agrophysics, Polish Academy of Sciences 
may improve the rheological properties of masa. Zepeda et al. (2011) studied maize grains of three varieties that were irradiated with electromagnetic fields and were then used to produce tortillas, observing changes to the physical quality of maize grains and tortillas. They showed that maize grains irradiated for $15 \mathrm{~min}$ increased strength and tortilla elongation, a parameter related to their rollability.

Nejayote is produced during the nixtamalization process and can be considered a highly contaminant wastewater which is discarded into the sewer system. In recent years, research efforts have been made to find novel uses for this by-product. Investigations have been performed to assess the potential of filtration to treat nejayote, an operation that results in filtrates with high calcium content (Valderrama-Bravo et al., 2012, 2013). In addition, some phytochemicals have been successfully extracted from nejayote (Gutiérrez-Uribe et al., 2010) which can be used as food additives to enhance fibre, calcium and ferulic acid content in bread (Acosta-Estrada et al., 2014). Finally, Valderrama-Bravo et al. (2016) reported that maize nixtamalization with nejayote lowered the microbiological load in masa, thus increasing its shelf life.

In this context, adding nejayote solids to nixtamal increases calcium carbonate content and significantly reduces the rheological parameters of the produced masa (Valderrama-Bravo et al., 2015). However, in order to achieve this, a centrifugation and a drying step must be added to obtain nejayote solids, which would involve greater time and costs for the process.

Some authors (Gutiérrez-Cruz et al., 2011; Zepeda et al. 2011) recommended using electromagnetic irradiation in order to increase the physical quality of maize grains and, consequently, of both masa and tortillas. Therefore, it is advisable to use technologies to improve the quality of maize during the nixtamalization process with nejayote.

In the masa and tortilla industry, it is essential to perform sensory analyses because the attributes affect the quality of food consumed by the population. Herrera et al. (2007) evaluated the organoleptic quality of ten types of tortillas in Texcoco, Mexico, finding that consumers preferred tortillas with pleasant odour and flavour that did not break when rolling them up. Thus, it is important to have reliable and specific techniques that contribute to the characterization and improvement of these foodstuffs in a friendly manner, which could be the case of electromagnetic methods (Hernández et al., 2012; 2016).

Therefore, the aim of this research was to expose maize grains to different electromagnetic field regimes and then carry out nixtamalization of these grains with a certain dilution of nejayote to assess microbiological and viscoelastic changes in masa, as well as evaluate the sensory quality of tortillas.

\section{MATERIALS AND METHODS}

Maize grains (M55xM54) used in the nixtamalization process were obtained from one simple cross of two inbred lines. The genotypes of white maize were generated by the National Research Institute for Forestry Agriculture and Livestock (INIFAP) in Texcoco, the State of Mexico, in the experimental station of $\mathrm{UACH}$ at Chapingo, the State of Mexico, during the spring-summer agricultural cycle in 2016.

The moisture and weight of 100 grains were determined using the procedure described by Serna-Saldivar et al. (1992). The hectolitre weight was evaluated using the 84-10 method (AACC, 2000). Grain hardness is a quality parameter of the maize used in nixtamalization, which is evaluated indirectly by the flotation index (Salinas et al., 1992).

Two samples of maize grains $(1 \mathrm{~kg})$ were treated with electromagnetic fields (EF) of $0.42 \mathrm{mT}$ (measured with F.W.Bell ${ }^{\mathbb{Q}}$ Gauss/Teslameter, 5070 model), at two exposure times, i.e. 7 and $12 \mathrm{~min}$, while placed in the middle of a solenoid (an area of the greatest magnetic induction). The irradiator device was developed and built by Dominguez Pacheco, and then used by the research group of ESIME-IPN (Gutiérrez-Cruz et al., 2011; RicoMartínez et al., 2014).

The microbiological analysis of nejayote was performed according to the Mexican standard (NOM-111SSA1-1994), using a serial dilution method to identify moulds, yeasts, total mesophyles and coliform bacteria. An aliquot $(1 \mathrm{ml})$ of each dilution was aseptically transferred into several Petri plates in two different culture media: potato dextrose agar (PDA; BIOXON) and malt extract agar (MEA; BIOXON), while tergitol was added to both media. The Petri plates were incubated (Precision Scientific $\operatorname{Mod} 815$ ) at $25^{\circ} \mathrm{C}$ for $48 \mathrm{~h}$ for bacteria, and for 4-5 days for moulds and yeasts. Colonies were counted and the average number of colonies per plate was multiplied by the dilution factor to obtain the number of organisms per gram in the original sample.

A factorial design $3^{2}$ with three replicates was used. The nejayote concentration factor in masa had three levels, i.e. the masa obtained from nixtamalized maize without nejayote (control masa, CM), the MN1 masa obtained from nixtamalized maize with 1:1 diluted nejayote ( $750 \mathrm{ml}$ water/750 $\mathrm{ml}$ whole nejayote), and the MN2 masa obtained from nixtamalized maize with 2:1 diluted nejayote $(1050 \mathrm{ml}$ water $/ 450 \mathrm{ml}$ whole nejayote). The time of maize irradiation by electromagnetic fields, with three levels (0, 7 and $12 \mathrm{~min})$, constituted the second factor. The $\mathrm{CM}, \mathrm{MN} 1$ and MN2 samples were prepared by cooking $500 \mathrm{~g}$ of maize in $1500 \mathrm{ml}$ water, $1500 \mathrm{ml}$ of 1:1 diluted nejayote, and $1500 \mathrm{ml}$ of 2:1 diluted nejayote, respectively, containing $5 \mathrm{~g}$ food-grade calcium hydroxide (Fermont, Monterrey N. L. México). Maize samples were cooked at $90^{\circ} \mathrm{C}$ for $40 \mathrm{~min}$ and then steeped for $12 \mathrm{~h}$. The cooking 
liquid was separated and the nixtamalized samples were washed with $500 \mathrm{ml}$ water, and then ground in a hand mill (Nixtamatic, Edo. Mex., México). The obtained masa was dried by means of a forced circulation air oven, at $55^{\circ} \mathrm{C}$ for $24 \mathrm{~h}$. The dried samples were pulverized using a hammer mill (Pulvex 200, Mexico) with a $0.8 \mathrm{~mm}$ mesh. The maize flours thus obtained were packed in hermetic polyethylene bags and stored at $4{ }^{\circ} \mathrm{C}$ until they were used. Flours were rehydrated to reach $54 \%$ moisture, in order to obtain rollable masa which was then shaped into discs (diameter $10.9 \mathrm{~cm}$; thickness $1.3 \mathrm{~mm}$; and weight $20 \mathrm{~g}$ ) using a manual tortilla machine. The discs were laid on a 'comal' and cooked (at $220^{\circ} \mathrm{C}$ ) for $30 \mathrm{~s}$ on one side, turned over and cooked for another $30 \mathrm{~s}$, and turned over again to cook until they formed ampoules. The masa (CM-7, CM-12, MN1-7, MN1-12, MN2-7 and MN2-12) were processed under the conditions presented in Table 1.

A decision was made to use dilutions instead of the whole nejayote for nixtamalizations because previous reports showed that masa obtained with the latter was hard and its viscoelastic modulus values were very high; whilst diluted nejayote produced masa with better viscoelastic behaviour (Valderrama-Bravo et al., 2015).

The agar plate method was employed to identify fungi colonies in the maize grains used in this research. Fifty maize grains were plated aseptically into several Petri plates using the two types of culture media mentioned above. The plated grains were incubated at $25^{\circ} \mathrm{C}$ for 5 days. At the end of incubation period, fungi growing out from grains on the agar were examined, counted and identified. Identification was based on the colony and morphology characters using specialized keys (Barnett and Hunter, 1998; Mathur and Kongsdal, 2003; Leslie and Summerell, 2008, Samson and Pitt, 1990; Pitt, 1979).

Table 1. Description of masa and tortillas code

\begin{tabular}{|c|c|c|c|c|}
\hline \multirow{2}{*}{$\begin{array}{l}\text { Treat- } \\
\text { ment }\end{array}$} & \multirow{2}{*}{$\begin{array}{c}\text { Exposure } \\
\text { times } \\
(\mathrm{min})\end{array}$} & \multirow{2}{*}{$\begin{array}{l}\text { Description } \\
\text { nixtamalization } \\
\text { agua/whole } \\
\text { nejayote } \\
(\mathrm{ml} / \mathrm{ml})\end{array}$} & \multicolumn{2}{|c|}{ Identification code } \\
\hline & & & Masa & Tortilla \\
\hline 1 & 0 & \multirow{3}{*}{0} & $\begin{array}{l}\text { CM } \\
\text { (Control) }\end{array}$ & $\mathrm{CT}$ \\
\hline 2 & 7 & & CM-7 & CT-7 \\
\hline 3 & 12 & & CM-12 & CT-12 \\
\hline 4 & 0 & \multirow{3}{*}{$50 / 50$} & MN1 & TN1 \\
\hline 5 & 7 & & MN1-7 & TN1-7 \\
\hline 6 & 12 & & MN1-12 & TN1-12 \\
\hline 7 & 0 & \multirow{3}{*}{$70 / 30$} & MN2 & TN2 \\
\hline 8 & 7 & & MN2-7 & TN2-7 \\
\hline 9 & 12 & & MN2-12 & TN2-12 \\
\hline
\end{tabular}

The microbiological analysis of masa was carried out according to the Mexican standard (NOM-111-SSA1-1994), using a serial dilution method for identifying moulds. A $10^{-1}$ dilution was obtained as follows: $10 \mathrm{~g}$ of each masa sample was aseptically mixed in a laboratory blender (Warring ${ }^{\circledR}$ ) with $90 \mathrm{ml} 0.1 \%$ sterile peptone water (BIOXON) for $30 \mathrm{~s}$. A $10^{-2}$ dilution was prepared by adding $1 \mathrm{ml}$ volume of this mixture to a test tube containing $9 \mathrm{ml}$ sterile peptone water $(0.1 \%)$. This method was repeated until a $10^{-4}$ dilution was obtained. Dilutions of $1 \mathrm{ml}$ were aseptically transferred into Petri plates with different culture media (PDA and MEA, plus tergitol; BIOXON), and then incubated at $25^{\circ} \mathrm{C}$ for 4-5 days. Colonies were counted and the average value per plate was multiplied by the dilution factor, providing the number of organisms per gram of the original sample. Single colonies were transferred aseptically to agar plates for further identification. Moulds were counted and categorized, based on their morphological features, colony size, shape and colour. Isolated fungi were identified at the genus level using Barnett and Hunter (1998) morphological keys, and at the species level for Acremonium according to Giraldo et al. (2015); for Fusarium specialized key Leslie and Summerell (2008) and for Penicillium Samson and Pitt (1990) and Pitt (1979) keys.

The viscoelastic parameters of masa, i.e. elastic $\left(G^{\prime}\right)$ and viscous $\left(\mathrm{G}^{\prime \prime}\right)$ moduli, were measured by running oscillatory tests in a TA Instruments Rheometer, model RT 20 Haake, New Castle (USA). The device employed to perform the test was a $35 \mathrm{~mm}$ rough plate. The reference methodology was developed according to ValderramaBravo et al. (2015).

Thirty consumers $(70 \%$ women and $30 \%$ men; aged 19-40 years) evaluated the colour, odour, taste, texture, rupture resistance, chewiness and the overall acceptability using a 9-point hedonic scale (Peryam and Pilgrim, 1957). The points were labelled, according to Hernández et al. (2012), as follows: I extremely like it (9), I really like it (8), I like it moderately (7), I like it slightly (6), I neither like nor dislike it (5), I dislike it slightly (4), I dislike it moderately (3), I dislike it (2), and I extremely dislike it (1). The test was conducted using a general randomized block design. The nine types of tortillas (Table 1) were processed from maize flour before passing them to consumers. Two tortillas of each treatment were served to consumers by a group of volunteers. Consumers responded to a questionnaire containing: (1) General information, and (2) The table to record their preferences. The duration time of the sensory test was $1 \mathrm{~h}$. The hedonic test was carried out in a single day, in a laboratory located in Cuautitlan Mexico, the State of Mexico.

Minitab $\AA$ Statistical software, version 16 (Minitab Inc., State College PA, USA), was used to analyze the data by applying an analysis of variance (ANOVA) at a probability of $\rho<0.05$. Differences between the means were determined using the Tukey test. All the measurements were carried out in triplicates. 


\section{RESULTS AND DISCUSSION}

Maize genotype M55xM54 contains an average of

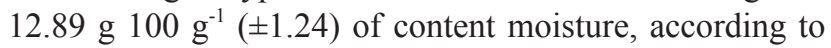
NMFX-FF-034/1-SCFI-2002 (SAGARPA, 2002), which

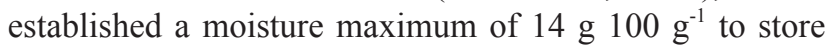
and preserve maize. The weight of 100 grains was $36.2 \mathrm{~g}$

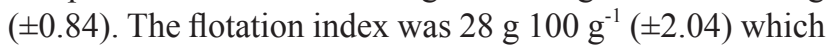
designates a hard grain according to NMFX-FF-034/1SCFI-2002 (SAGARPA, 2002). Therefore, the cooking time of maize was established, in relation to the results of the flotation index, as $40 \mathrm{~min}$. The hectolitre weight was $75.75 \mathrm{~kg} \mathrm{hl}^{-1}( \pm 0.35)$. The Mexican Official Standard NMX-FF-024/1-SCFI-2002 (SAGARPA, 2002) establishes a hectoliter weight minimum of $74 \mathrm{~kg} \mathrm{hl}^{-1}$, and a flotation

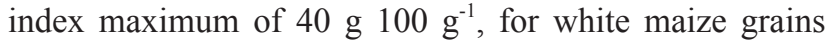
used in the elaboration process of tortillas.

The microbiological analysis of nejayote showed no growth of fungi, yeast and bacteria which, according to Valderrama-Bravo (2016), could be due to the high $\mathrm{pH}$ of the liquid (11.89 \pm 0.06$)$. Figure 1 shows fungi growth in non-irradiated (control) and irradiated ( 7 and $12 \mathrm{~min}$ ) maize grains M55xM54 in two different culture media (PDA and MEA). Fusarium verticillioides, Fusarium graminearum, Penicillium oxalicum and Penicillium chrysogenum were isolated from the control grain. The statistical analysis conducted did not show any significant differences $(\rho>$ 0.05 ) among the non-irradiated and irradiated maize grains for Penicillium species. During its growth and harvest, maize is colonized by different fungi genera, such as Fusarium, Alternaria and Penicillium; while the genera Aspergillus and Penicillium can develop during storage (Lacey, 1989). Penicillium grows in both non-irradiated
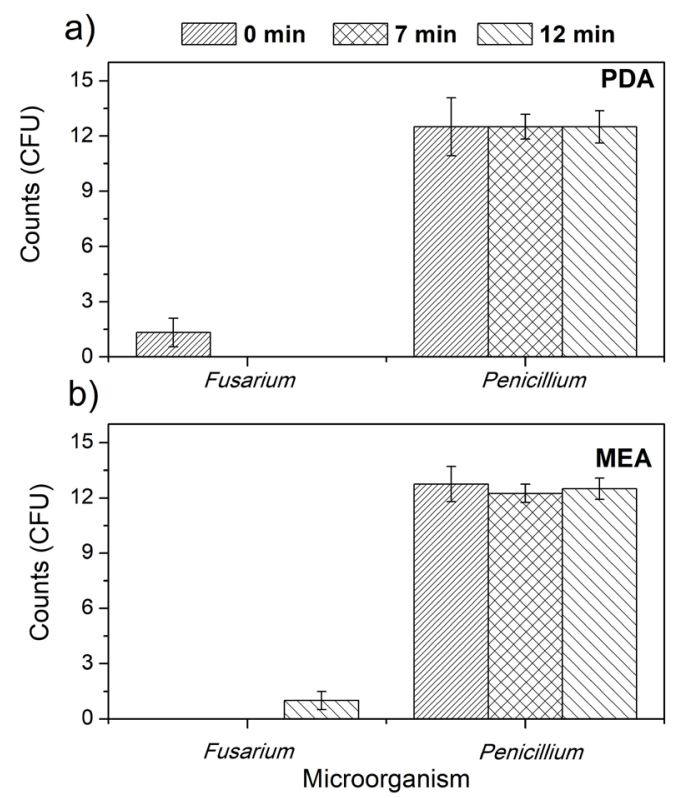

Fig. 1. Fungi genera in non-irradiated $(0 \mathrm{~min})$ and irradiated (7 and $12 \mathrm{~m}$ in) maize grains, grown in two media: a - PDA and $\mathrm{b}-$ MEA. and irradiated maize on PDA at about $13 \mathrm{CFU} \mathrm{g}^{-1}$, while on MEA the number of colonies is 11-12 CFU g ${ }^{-1}$. Therefore, the EF application in maize did not show an inhibitory effect on the Penicillium species identified. Penicillium kernel infection can occur in the field or in the storage, caused by an internal discoloration ('Blue eye') of the embryo (Stack, 2000). In contrast, both species of Fusarium were completely inhibited in the maize irradiated for $7 \mathrm{~min}$. Fusarium is the principal genus ear rot of corn.

Figure 2 shows the growth of moulds in masa. $F$. verticillioides and $F$. graminearum were absent in all masa samples, and it has been reported that the nixtamalization process reduces their growth in about 50-80\% (Palencia et al., 2003; Voss et al., 2001).

On the other hand, in the CM masa (not irradiated), CM-7 and CM-12 min (irradiated 7 and $12 \mathrm{~min}$, respectively) Acremonium zea (Current Name Sarocladium zea) specie was able to grow, contrary to the masa obtained from maize nixtamalized with nejayote. The genus Acremonium has a worldwide distribution and is reported as a soil-borne fungus while the Acremonium zeae species is one of the most prevalent endophyte fungi colonist of preharvest corn, producing symptomless infection of corn seeds. It has been isolated from the stalks of mature plants and grows most vigorously in artificial media containing xylan as carbon source (Nicolau de Almeida, 2011; Bischoff et al. 2009). It possesses a suite of hemicellulolytic enzymes such as xylanase, xylosidase and arabinofuranosidase, which reduce corn fibre (Bischoff et al., 2011). Endophytes that produce cellulases and hemicelullases should be able to compete with other types of fungi, thus optimizing their growth in masa. Wicklow et al. (2005) showed that organic extracts from maize grains fermented by Acremonium zeae produce pirrodicines $\mathrm{A}$ and $\mathrm{B}$, which have antagonistic effects against Aspergillus flavus and Fusarium verticillioides, which might explain the absence of Fusarium species in masa.

Even though Acremonium is an innocuous mould, it could potentially reduce the physical quality of masa and, as a consequence, of fermentation processes. Using nejayote as nixtamalization water could inhibit the growth of Acremonium, since it contains phenolic compounds (Valderrama et al., 2016). However, the MN1 and MN17 masa samples developed other ear rot genera, such as Alternaria, Cladosporium and Penicillium. Alternaria is frequently found in cereals, causing grey discoloration and producing mycotoxins, while Cladosporium ear rot is a field mould whose toxicity has not been clearly defined, but the growth of these species can also result in grey discoloration (Pitt and Hocking, 2009). Interestingly, Fig. 2c shows no microorganism growth for the MN1-12 masa samples, which could indicate that a higher sanitary quality of masa is best achieved by the synergistic effect between the application of EF and nejayote as nixtamalization water. 
a) $Z Z 7 \mathrm{CM} \quad \rightleftharpoons \mathrm{MN} 1$ WOMN2
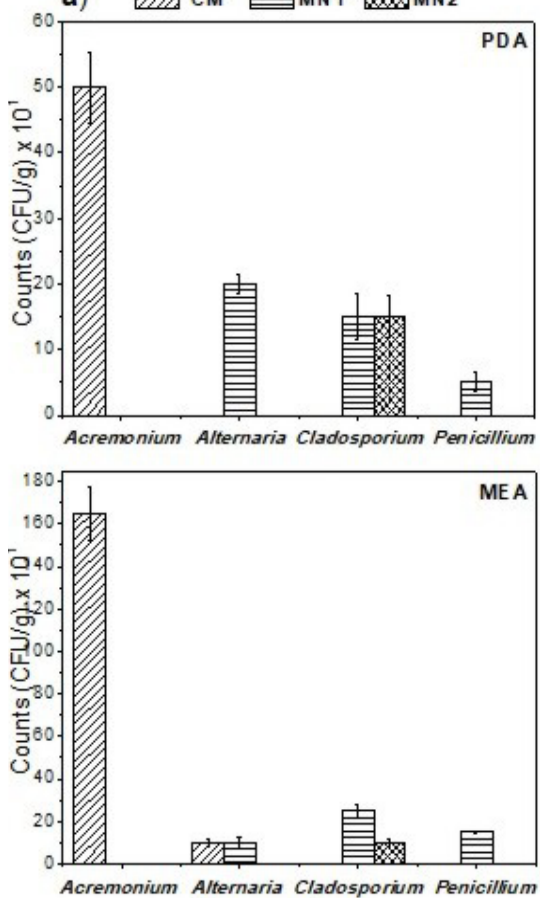

b) एय CM-7 ШMN1-7
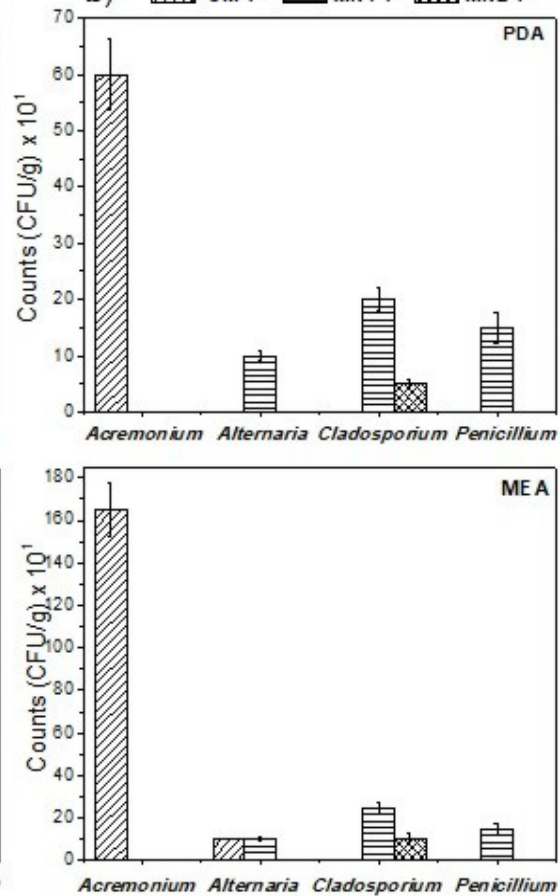

C)
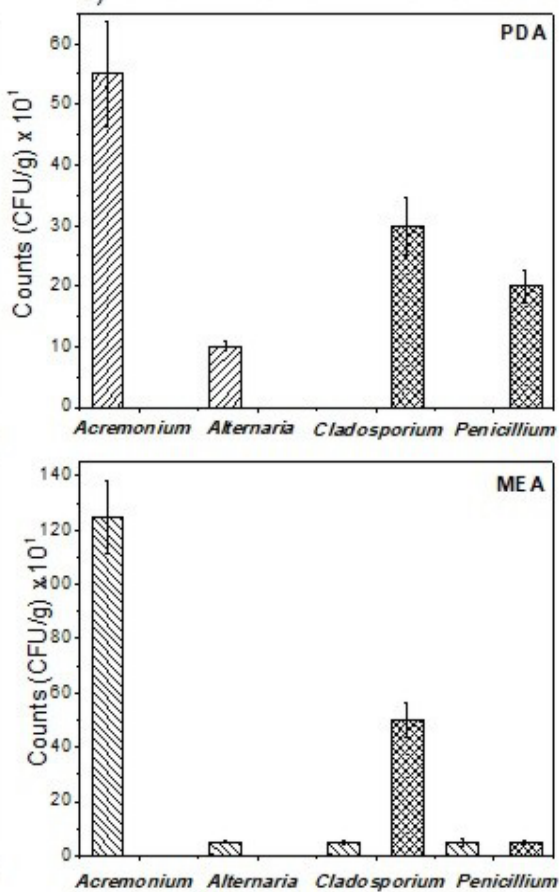

Fig. 2. Fungi genera of masa grown in two media PDA and MEA obtained from maize grains: a - non-irradiated ( 0 min) and irradiated $\mathrm{b}-7 \mathrm{~min}$ and $\mathrm{c}-12 \mathrm{~min}$.

Figure 3 shows the results of the measurement of viscoelastic parameters, elastic $\left(\mathrm{G}^{\prime}\right)$ and viscous $\left(\mathrm{G}^{\prime \prime}\right)$ moduli, versus the frequency of the masa obtained from maize treated with EF and nixtamalized with nejayote. Statically, data showed significant differences $(\mathrm{p}<0.05)$ among all treatments. Masa showed values of $\mathrm{G}^{\prime}$ higher than $\mathrm{G}^{\prime \prime}$ which indicates an elastic behaviour. The CM-12 masa showed the highest values of $\mathrm{G}^{\prime}$ and $\mathrm{G}^{\prime \prime}$, while $\mathrm{MN} 1, \mathrm{MN} 2$ and MN1-7 displayed the lowest values. The results indicate that the EF application to maize nixtamalized with nejayote modifies the viscoelastic modulus of the produced masa. In this study, treating maize with EF for 12 min could have modified the structure of the starch granules, causing a concomitant change in the viscoelastic parameters of masa.

Non-irradiated and nejayote-nixtamalized maize did not show any significant differences in the elastic modulus of the MN1 and MN2 masa samples, and their modulus were lower than in CM. On the other hand, the masa obtained from irradiated and nejayote-nixtamalized maize (MN17, MN1-12, MN2-7 and MN2-12) showed significant differences. These results differ from those presented by Valderrama-Bravo et al. (2015), because they nixtamalized maize with nejayote and added nejayote solids to masa. The authors attributed the increases in masa elastic modulus to the calcium carbonate contained in nejayote, which gives greater stiffness to the masa. In the present study, masa was obtained from maize flour, thus showing a homogeneous particle size, in contrast to the above-mentioned study where masa was prepared in a manual wet mill. Particle size uniformity may facilitate the absorption and diffusion

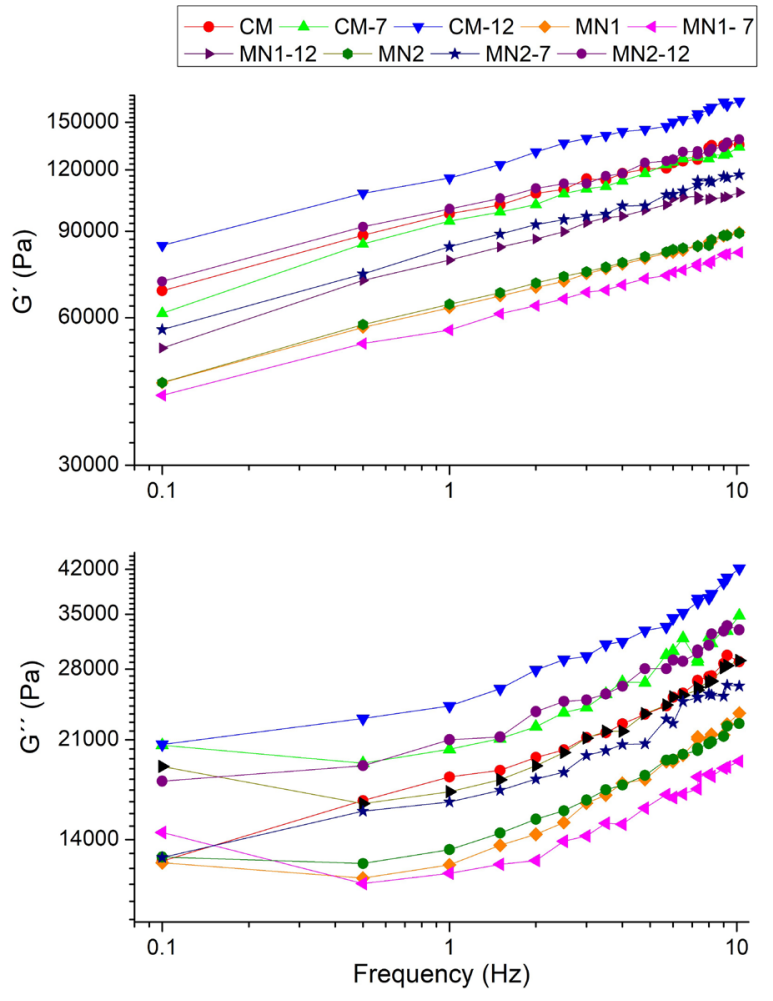

Fig. 3. Elastic (G') and viscous (G") moduli of the masa obtained from maize grains irradiated by electromagnetic fields and nixtamalized with nejayote. 
of water molecules, so they could interact better with the polysaccharides present in nejayote (mainly arabinoxylans) (Niño-Medina et al., 2009). Arabinoxylans are similar to other hydrocolloids, such as carboxymethylcellulose, and gums like guar, xanthan or Arabic, which display thickening, stabilizing and gelling functional properties (Gurkin, 2002). Another functional compound found at high concentrations in nejayote is ferulic acid (Gutiérez-Uribe et al., 2010).

It is possible that these compounds influence the elastic behaviour of masa. On the one hand, arabinoxylans are non-starch polysaccharides found in the aleurone and pericarp, which form covalent and physical linkages with other cell wall components, resulting in a structure that is insoluble in water, but soluble under alkaline conditions. On the other hand, ferulic acid can crosslink with polysaccharide chains to form ferulic acid dehydrotrimers and dehydrodimers, which are relevant to the gelation process of arabinoxylans (Berlanga-Reyes et al., 2011). Given that the nixtamalization process is an alkaline cooking, which causes hydrolysis of cell wall components of the pericarp, the presence of a part of arabinoxylans and ferulic acid is expected in the cooking liquid (nejayote). Ayala-Soto et al. (2014) obtained arabinoxylans from different maize fibres, and the arabinoxylan gels produced with nejayote presented a weaker structure, showing lower G' value, while the elastic modulus of gels produced with white maize fibres were higher. This fact was attributed to a higher ferulic acid concentration, and a lower ferulic acid dehydrotrimer concentration, during the hydrolysis in nixtamalization. In this study, the ferulic acid, ferulic acid dehydrotrimer and arabinoxylans were not evaluated. Nevertheless, we suppose that the interactions between these components could influence the elastic behaviour ( $\mathrm{G}^{\prime}$ ) of the MN1 and MN2 masa samples which contain nejayote, which is why the values were the lowest. This contrasts with Valderrama-Bravo et al. (2015), who found higher elastic modulus values when nixtamalizing maize with nejayote. Izydorczyk and Biliaderis (2007) mentioned that arabinoxylans and ferulic acid concentrations might vary depending on the grain genotype, environmental factors and maturity stages. The maize M55xM54 employed in the present work was obtained by crossing two inbred lines, thus possessing different maize characteristics than the grains used by Valderrama-Bravo et al. (2015). Also, the authors used control masa, masa nixtamalized with nejayote, and masa with added nejayote solids, all of which were processed by wet-milling, whereas, as mentioned above, the masa used in this study was made from nixtamal (whole maize hominy) flour. During wet-milling, nixtamal is ground 3-4 times, which allows starch and arabinoxylans to gel, developing an increase in the elastic modulus of masa.

Ayala-Soto et al. 2014 supported this fact, as they worked with arabinoxylans from maize fibres by wet-milling, and their results showed the gel structure to be more elastic and stiffer. On the other hand, by applying EF to maize grains, their molecular structure could be modified. Aladjadjiyan (2002) showed that the application of EF to biological materials developed molecular alterations that changed the path of ions. Therefore, it could be possible for nejayote compounds to develop interactions with the altered molecules in grains treated with EF, which could explain why the masa obtained in this study showed lower stiffness.

Figure 4 shows the results of consumer preferences regarding odour, colour, taste, texture, chewiness and the overall attributes. The sensory test of nine different tortillas showed differences in preferences for the evaluated attributes, according to the scale used in the evaluation.

The scores for tortillas CT, CT-7 and TN1 with TN212 , indicated that the EF irradiation time and nejayote concentration are the factors influencing the final product. Although TN2 had a high odour score, due to some nejayote compounds that could improve tortilla flavour, its texture and chewiness showed low scores. The reason for this could be the lower elastic module value of MN2 (Fig. 3) when compared to the masa obtained from irradiated maize. TN2-12 had the highest score of the overall attributes, texture, chewiness and taste, whereas CT showed the lowest score. The results indicated that a combination of EF irradiation of maize grains, and the use of diluted nejayote as nixtamalization water, improved tortilla quality. We attribute the changes observed mainly to the modifications of the starch granule structure in irradiated maize, which could affect its functional properties. Ponne and Bartels (1995) reported that the electromagnetic waves were discrete quanta, absorbed by the matter. The quantum energies of radio waves are several orders of magnitude too low to break chemical bonds. However, there are structures in biological materials which may be affected by very low energies, such as hydrogen bonds, where proton displacement can occur.

Zepeda et al. (2011) demonstrated increases in the force and elongation of the tortilla obtained from maize treated with electromagnetic fields for $15 \mathrm{~min}$. Elongation

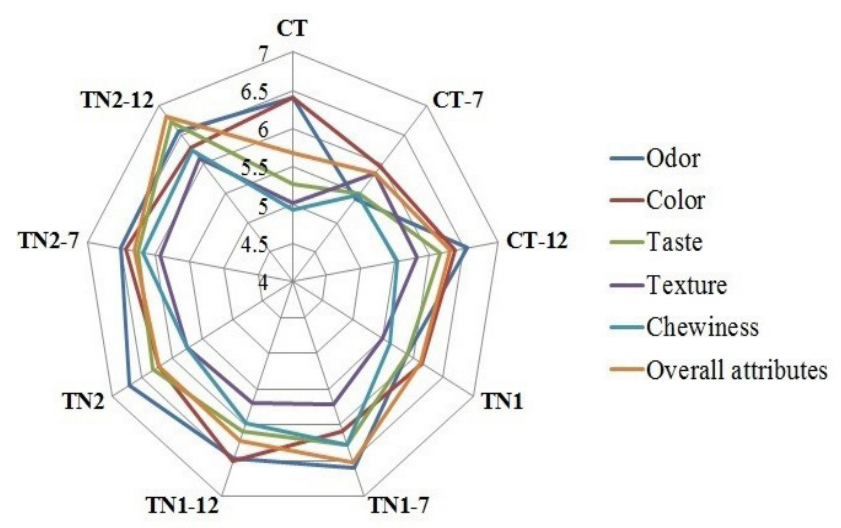

Fig. 4. Sensory test of tortillas shows differences in evaluated attributes. 
is a determinant parameter in the rollability and sensorial quality of tortillas (Herrera et al., 2007). Other nejayote compounds, such as calcium carbonate, arabinoxylans and fibre, might also affect the physical properties of masa and, in consequence, the sensorial attributes of tortillas.

\section{CONCLUSIONS}

1. The sanitary quality of masa is improved by the synergistic effect between the application of electromagnetic fields and the nixtamalization of maize with nejayote.

2. Electromagnetic fields applied in maize grains increases viscoelastic modulus; conversely, the masa obtained from irradiated maize and nixtamalized with nejayote showed lower stiffness. This indicates that nejayote compounds can interact with maize molecules that have been modified by electromagnetic fields.

3. The irradiation of maize grains by electromagnetic fields and the use of diluted nejayote during the nixtamalization process improve the sensory attributes of tortillas. The highest score of the overall attributes was presented in the tortillas produced by a combination of 12 min irradia-

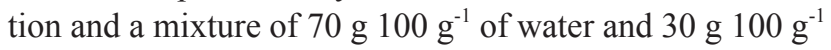
of whole nejayote.

\section{ACKNOWLEDGMENTS}

The authors wish to thank Dra. Martha Yolanda Quezada Viay for the technical support provided, the National Research Institute for Forestry Agriculture and Livestock (INIFAP), in Texcoco, State of Mexico, for providing the maize grains. The authors also thank MSc. Elisa Dominguez-Hernández for the technical review of this work.

Conflict of interest: The Authors do not declare any conflict of interest.

\section{REFERENCES}

AACC International, 2000. Approved methods of the American Association of Cereal Chemists. Method 84-10, St. Paul, MN, USA.

Acosta-Estrada B., Lazo-Vélez M., Nava-Valdez Y., GutiérrezUribe J., and Serna-Saldívar S., 2014. Improvement of dietary fiber, ferulic acid and calcium contents in pan bread enriched with nejayote food additive from white maize (Zea mays). J. Cereal Sci., 60, 264-269.

Aladjadjiyan A., 2002. Study of the Influence of Magnetic Field on Some Biological Characteristics of Zea mays. J. Cent. Eur. Agric., 3, 89-94.

Ayala-Soto F., Serna-Saldivar S., Pérez-Carrillo E., GarcíaLara S., 2014. Relationship between hydroxicinnamic profile with gelation capacity and rheological properties of arabinoxylans extracted from different maize fiber sources. Food. Hydrocolloid., 39, 280-285.

Barnett H.L. and Hunter B.B., 1998. Illustrated Genera of Imperfect Fungi. APS Press, The American Phytophathological Society, St. Paul, MI, USA.
Bello-Pérez L. A., Osorio-Díaz P., Agama-Acevedo E., NúñezSantiago C., Paredes-López O., 2002. Chemical, physicochemical and rheological properties of masas and nixtamalized corn flour. Agrociencia, 36, 319-328.

Berlanga-Reyes C.M., Carvajal-Millán E., Lizardi-Mendoza., Islas-Rubio A., and Rascón-Chu A., 2011. Enzymatic cross-linking of alkali extracted arabinoxylans: gel rheological and structural characteristics. Int. J. M. Sci., 12, 5853-5861.

Bischoff K.M., Wicklow D.T., Jordan D.B., De Rezende S.T., Liu S., Hughes S.R., and Rich J.O., 2009. Extracellular hemicellulolytic enzymes from the maize endophyte Acremonium zeae. Curr. Microbiol., 58, 499-503.

Bischoff K.M., De Rezende S.T., Larson T.M., Liu S., Hughes S.R., and Rich J.O., 2011. Purification and characterization of arabinofuranosidase from the corn endophyte Acremonium zeae. Biotechnol. Lett., 33, 2013-2018.

Fernández-Muñoz J.L., Acosta-Osorio A. A., Gruintal-Santos M.A., and Zelaya-Angel O., 2011a. Kinetics of water diffusion in corn grain during the alkaline cooking at different temperatures and calcium hydroxide concentration. J. Food. Eng., 106, 60-64.

Fernández-Muñoz J.L., Acosta-Osorio A.A., Zelaya-Angel O., Rodríguez-García M.E., 2011b. Effect of calcium content in the corn flour on RVA profiles. J. Food Eng., 102, 10-103.

Giraldo A., Gené J., Sutton D.A., Madrid H., De Hoog G.S., Cano J., and Guarro J., 2015. Phylogeny of Sarocladium (Hypocreales). Persoonia-Molecular Phylogeny. Evolution of Fungi, 34(1), 10-24.

Gurkin S., 2002. Hydrocolloids- Ingredients that add flexibility to tortilla processing. Cereal Food World, 47, 41-43.

Gutiérrez-Cortez E., Rojas-Molina I., Zambrano-Zaragoza M.L., Espinosa-Arbelaez D., Rojas A., García J.C., CornejoVillegas M.A., and Rodríguez-García M.E., 2016. The mass transport phenomenon through pericarp during the nixtamalization process. Food Bioprod. Process., 100, 477-486.

Gutiérrez-Cortez E., Rojas-Molina I., Rojas A., Arjona J.L., Cornejo-Villegas M.A., Zepeda-Benítez Y., VelázquezHernández R., Ibarra-Alvarado C., and RodríguezGarcía M.E., 2010. Microstructural changes in the maize kernel pericarp during cooking stage in nixtamalization process. J. Cereal Sci., 51, 81-88.

Gutiérrez-Cruz D., Zepeda Bautista R., Hernández Aguilar C., Domínguez Pacheco F.A., Cruz Orea A., and Bonilla López J.L., 2011. Physical characteristics of grains of maize pre-sowing treated by electromagnetic fields. Acta Agrophys., 18, 17-31.

Gutiérrez-Uribe J., Rojas-García C., García-Lara S., and Serna-Saldívar S., 2010. Phytochemical analysis of wastewater (nejayote) obtaneid after lime-cooking of different types of maize processed into masa for tortillas. J. Cereal. Sci., 52, 410-416.

Hernández-Aguilar C., Domínguez-Pacheco F.A., Cruz-Orea, A., Herrera-Corredor A., Gutierrez-Cruz D., ZepedaBautista R., and Ramírez M.E., 2012. Optical absorption coefficient of different tortillas by photoacoustic spectroscopy. Afr. J. Biotechnol., 11, 1516-15922.

Hernández-Aguilar C., Domínguez-Pacheco A., Cruz-Orea A., Podleśna A., Ivanov R., Carballo Carballo A., PérezReyes C., Sánchez-Hernández G., Zepeda-Bautista R., López-and Bonilla J.L., 2016. Laser bioestimulation in plants and seeds (in Spanish). Gayana. Bot., 73, 132-149. 
Herrera C., Saidu E., Khachatryan J., Prinyawiwatkul W., Carballo C., and Zepeda B., 2007. Identifying drivers for consumer acceptance and purchase intent of corn tortilla. J. Food. Sci., 72, 727-731.

Izydorczyk M.S. and Biliaderis C.G., 2007. Arabinoxylans: Technologically and nutritionally functional plant polysaccharides. In: Functional Food Carbohydrates (Eds C.G. Biliaderis, M.S. Izydorczyk). CRC Press, Boca Raton, FL, USA.

Lacey J., 1989. Pre-and post-harvest ecology of fungi causing spoilage of foods and other stored products. J. Appl. Bacteriol., 67, 11-25.

Leslie J.F. and Summerell B.A., 2008. The Fusarium laboratory manual. J. Wiley and Sons, New York, USA.

Martínez-Bustos F., Martínez-Flores H., Sanmartín-Martínez E., Sánchez- Sinencio F., Chang Y., Barrera-Arellano D., and Ríos E., 2001. Effect of the components of maize on the quality of masa and tortillas during the traditional nixtamalization process. J. Sci. Food Agr., 81, 1455-1462.

Mathur S.B. and Kongsdal O., 2003. Common laboratory seed health testing methods for detecting fungi. International Seed Testing Association, Bassersdorf, Switzerland.

Nicolau de Almeida M., Monteze G.V., Bischoff K.M., Falfoski D.L., Liparini P.O., Dayelle S.P.O.G., and Tavares R.S., 2011. Cellulases and hemicellulases from endophytic acremonium species and its application on sugarcane bagasse hydrolysis Appl. Biochem. Biotechnol., 165, 594-610.

Niño-Medina G., Carvajal-Millan E., Lizardi J., Rascon-Chu A., Marquez-Escalante J., and Gardea A., 2009. Maize processing waste water arabinoxylans: gelling capability and cross-linking content. Food Chem., 115, 1286-1290.

Palencia E., Torres O., Hagler W., and Meredith F., 2003. Total fumonisins are reduced in tortillas using the traditional nixtamalization method of Mayan communities. J. Nutr., 133, 3200-3203.

Peryam D.R. and Pilgrim F.J., 1957. Hedonic scale method of measuring food preferences. Food Technol., 11, 9-14.

Pitt J.I., 1979. The genus Penicillium and its teleomorphic states Eupenicillium and Talaromyces. Academic Press Inc., London, UK.

Pitt J.I. and Hocking A.D., 2009. Fungi and Food Spoilage. Springer, New York, USA.

Ponne C., and Bartels V., 1995. Interaction of electromagnetic energy with biological material-relation to food processing. Int. J. Radiat. Phys. Ch., 45, 591-607.

Rico-Martinez F., Dominguez-Pacheco F.A., Hernandez-Aguilar C., Paniagua-Pardo G., and Martinez-Ortiz E., 2014. Effects of magnetic field irradiation on broccoli seed with accelerated aging. Acta Agrophysic., 21, 63-73.

Rodríguez M., Yañez-Limón J., Alvarado-Gil J., SánchezSinencio F., Figueroa F., Martínez B., Martínez-Montes J.L., González-Hernández J., and Silva Miranda L.C.M., 1996. Influence of the structural during alkaline cooking on the terminal, rheological, and dielectric properties of maize tortillas. Cereal. Chem., 73, 593-600.

SAGARPA, Secretariat of Agriculture, Fisheries and Food, 2002. Mexican Standard NMXFF- 034/1-SCFI-2002. Non industrialized food products for human consumption. Cereals.
White corn for alkaline process of corn tortillas and nixtamalized corn products. Specifications and test method. General Direction of Standards, SAGARPA, Mexico, D.F.

Salinas M., Martínez B., and Gomez H., 1992. Comparison of methods to measure the hardness of corn (Zea mays L.) (in Spanish). Arch. Latinoam. Nutr., 42, 59-63.

Samson R.A. and Pitt J.I., 1990. Modern concepts in Penicillium and Aspergillus classification. Plenum Press, New York, USA.

SSA, Secretariat of Health and Assistance, 1994. Official standard mexicana NOM-111-SSA1., 1994. Method for account of molds and yeasts in food. General Direction of Standards, SSA, Mexico, D. F.

Serna-Saldivar S.O. and Chuck-Hernández C., 2016. Tortillas. Reference Module in Food Science, from Encyclopedia of Food and Health, 319-325.

Serna-Saldívar S., Rooney L., and Greene L., 1992. Effects of lime treatment on the bioavailability of calcium in diets of tortillas and beans: bone and plasma composition in rats. Cereal Chem., 69, 78-81.

Stack J., 2000. G1408 Grain molds and micotoxins in corn. Cooperative Extension, Institute of Agriculture and natural resources. University of Nebraska-Lincoln. On Line http:// digitalcommons.unl.edu./extensionhist/89

Valderrama-Bravo C., Gutiérrez-Cortez E., ContrerasPadilla M., Oaxaca-Luna A., Del Real López A., Espinosa-Arbelaez D. G., and Rodríguez-García M.E., 2013. Physic-mechanic treatment of nixtamalization byproduct (nejayote). CyTA-J. Food, 11(SI), 75-83.

Valderrama-Bravo C., Gutiérrez-Cortez E., Contreras-Padilla M., Rojas-Molina I., Mosquera J., Rojas-Molina A., Beristain F., and Rodríguez-García M.E., 2012. Constant pressure filtration of lime water (nejayote) used to cook kernels in maize processing. J. Food Eng., 110, 478-486.

Valderrama-Bravo C., López-Ramírez Y., Jiménez-Ambriz S., Oaxaca-Luna A., Domínguez-Pacheco A., HernándezAguilar C., and Moreno-Martínez E., 2015. Changes in chemical, viscoelastic, and textural properties of nixtamalized dough with nejayote. LWT - Food. Sci. Technol., 61, 496-502.

Valderrama-Bravo C., Pacheco-Domínguez A., HernándezAguilar C., Flores-Saldaña N., Villagran-Ortíz P., PerezReyes C., Sánchez-Hernández G., and Oaxaca-Luna A., 2016. Effect of nixtamalized maize with lime water (nejayote) on rheological and microbiological properties of masa. J. Food Process. Pres., 41, 1-9.

Voss K., Poling S., Meredith F., Bacon C., and Saunders D., 2001. Fate of fumonisins during the production of fried tortilla chips. J. Agr. Food Chem., 49, 3120-3126.

Wicklow D.T., Roth S., Deyrup S.T., and Gloer J.B., 2005. A protective endophyte of maize: Acremonium zeae antibiotics inhibitory to Aspergillus flavus and Fusarium verticillioides. Mycol. Res., 109, 610-618.

Zepeda R., Hernández C., Suazo F., Domínguez A., Cruz A., Martínez E., and Hernández L.M.S., 2011. Physical characteristics of maize grain and tortilla exposed to electromagnetic field. Int. Agrophys., 25, 389-393. 